\title{
GLUTEAL ACTIVATION AND INCREASED FRONTAL PLANE PROJECTION ANGLE DURING A STEP-DOWN TEST IN YOUNG WOMEN
}

original paper

(1) University School of Physical Education in Wrocław

DOI: https://doi.org/10.5114/hm.2018.73614

\author{
ALEXANDRE CARVALHO BARBOSA ${ }^{1}$, EDGAR RAMOS VIEIRA ${ }^{2}$, \\ MICHELLE ALMEIDA BARBOSA ${ }^{1}$, ILHA FERNANDES ${ }^{1}$, MARCELA DAMÁZIO ${ }^{1}$, \\ BÁRBARA BADARÓ ${ }^{1}$ \\ ${ }^{1}$ Department of Physical Therapy, Musculoskeletal Research Group - NIME, Federal University of Juiz de Fora, \\ Governador Valadares, Brazil \\ ${ }^{2}$ Department of Physical Therapy, Florida International University, Miami, USA
}

\begin{abstract}
Purpose. To investigate how the activation of gluteus maximus and gluteus medius interacts with different frontal plane projection angles (FPPA) in healthy young women presenting dynamic knee valgus in one limb while performing the step-down test. Methods. The total of 18 young women presenting FPPA $>15^{\circ}$ during the step-down test in one limb (dynamic knee valgus) were assessed. The other limb should present less than $15^{\circ}$ for comparisons. The amplitude of muscle activation was assessed through surface electromyography of gluteus medius and gluteus maximus during 8 subsequent weight bearing step-down tests. Results. FPPA was positively correlated with gluteus maximus activation and with the assessed side showing FPPA $>15^{\circ}$, which also revealed increased activation of gluteus maximus. No differences were noted for gluteus medius. The principal component analysis explained $73 \%$ of the variance in 2 components, with gluteus maximus explaining $48 \%$ of the variance on the 1st component. Gluteus medius explained $25 \%$ on the 2 nd component.
\end{abstract}

Conclusions. Gluteus maximus seems to be a major component to explain dynamic knee valgus in women without symptoms of patellofemoral pain, probably owing to weakness and lack of stabilization of other proximal muscles of the hip-knee complex during the task.

Key words: assessment, knee, hip, valgus, electromyography

\section{Introduction}

Gluteal weakness is often associated with abnormal femoral movements in internal rotation associated to adduction of the hip, leading the knee to move medially on the frontal plane [1]. The misalignment may change the knee kinematics, increasing lateral forces acting on the patella and the occurrence of patellofemoral pain (PFP) [2]. Young women (18-35-year-old) are more affected and show greater changes in lower limb kinematics than age-matched men [3-7]. A systematic review noticed increased dynamic valgus of the knee and increased joint load in women compared with men during landing and pivoting movements [8]. During weight bearing activities, excessive dynamic knee valgus seems to be controlled by increased strength and activation of muscles that oppose the internal rotation associated with the adduction of the femur [9]. A study [10] assessed kinematic variables of the hip and the level of activation of hip muscles while running and landing from a jump, as well as during a stepdown test. The results showed decreased hip muscle activation in females with PFP compared with painfree controls.

The frontal plane projection angle (FPPA) is a twodimensional measurement often used to assess knee

Correspondence address: Alexandre Carvalho Barbosa, Musculoskeletal Research Group - NIME, Department of Physical Therapy, Federal University of Juiz de Fora, Avenida Dr. Raimundo Monteiro Rezende, 330, Centro, Governador Valadares, Minas Gerais, Brazil, CEP 35010-177, e-mail: alexwbarbosa@hotmail.com

Received: September 21, 2017

Acepted for publication: December 8, 2017

Citation: Barbosa AC, Vieira ER, Barbosa MA, Fernandes I, DamázioM, Badaró B. Gluteal activation and increased frontal plane projection angle during a step-down test in young women. Hum Mov. 2018;19(1):64-70; doi: https://doi.org/10.5114/ hm.2018.73614. 
kinematics during closed kinetic chain activities [11]. FPPA is related to knee pain severity [12], the prediction of PFP [13], and the interaction between hip abductor isometric torque [14]. Also, passive hip internal rotation range of movement predicts the occurrence of high FPPA during single leg squatting [14].

Surface electromyography (sEMG) can assess hip muscles activation during dynamic knee valgus, highlighting the important role of the gluteus medius to lower limb kinematics $[1,15]$. However, no association was observed between the FPPA of the knee and strength of posterolateral hip muscles in a sample with PFP [11]. In a recent study, deficits of strength (28\%, approximately) were observed on hip extensors in women with PFP compared with the control group [11]. Another study suggested an association between gluteus maximus weakness and PFP [12]. Additionally, a systematic review with meta-analysis showed inconclusive outcomes to determine whether deficits in hip muscle strength are predisposing factors or a consequence of PFP [16]. The gluteus maximus muscle is a powerful hip extensor and lateral rotator [17], acting in synergy with gluteus medius to dynamically stabilize the hipknee complex [18]. Souza and Powers [10] showed increased activation of gluteus maximus as an attempt to stabilize the hip joint in subjects with PFP and compensate gluteal weakness during weight bearing activities.

Preliminary evidence for preventive intervention could be provided by identifying the activation pattern on the main gluteal muscles in young women without $\mathrm{PFP}$, who present dynamic knee valgus (FPPA $>15^{\circ}$ ). Future degenerative changes due to excessive retropatellar overpressure could be prevented by focal assessments and interventions [19].

Therefore, the purpose of this study was to investigate how the activation of gluteus maximus and gluteus medius interacts with FPPA in healthy young women while performing the weight bearing step-down test.

\section{Material and methods}

\section{Participants}

This was a non-randomized cross-sectional study, developed at the facilities of the Department of Physical Therapy of the Federal University of Juiz de Fora - Campus Governador Valadares, Brazil. Sample selection was carried out by a public call in the city of Governador Valadares. The total of 18 adult female subjects ( $22 \pm 2$ years of age, $165 \pm 6 \mathrm{~cm}, 58 \pm 8 \mathrm{~kg}$ ) participated in the study. Inclusion criteria were to present with a FPPA greater than $15^{\circ}$ during the stepdown manoeuvre in one limb. The other limb should present less than $15^{\circ}$ for comparisons. Among the exclusion criteria, there were pharmacological treatment for osteomioarticular pathologies, presenting signals or medical diagnosis of intervertebral disc herniation, hip, or knee degenerative injuries, overweight or obesity, and history of lower limb surgery.

\section{Knee angle assessment}

All procedures were conducted in a well lit reserved room with a non-reflective background to allow privacy. A camera (Coolpix S2700 16 MP, Nikon, Tokyo, Japan) was fixed and levelled on a tripod $3 \mathrm{~m}$ away from the subject horizontally and $0.85 \mathrm{~m}$ above the floor. Digital images were acquired in the continuous mode. All images were analysed with the use of the PAS/SAPO software (http://sapo.incubadora.fapesp.br) [20]. A plumb line was fixed on the roof with green cylinders $1 \mathrm{~m}$ apart from each other to calibrate the software.

A trained examiner identified the following anatomical landmarks through palpation: the midpoint of the ankle malleoli, the midpoint of the femoral condyles, and $30 \mathrm{~cm}$ above the knee on the proximal thigh along with a line from the anterior superior iliac crest (ASIS) [21]. Adhesive hypoallergenic tapes with attached reflexive green cylinders were positioned on the body landmarks for subsequent angle calculation. Subjects were instructed to stand up at a $20-\mathrm{cm}$ step pad parallel to the plumb line and perpendicular to the camera.

Both lower limbs were assessed. The starting position was standing on the step pad [22] with arms crossed against the chest. The subjects were asked to step down, touch their toe to the ground, and return to the starting position. The test was standardized: 2 seconds for the descent phase, 1 second to touch the ground, and 2 seconds to return [11]. A chronometer was used to control the procedure. The first two trials were performed as familiarization and the obtained mean values from the last 8 trials were used for statistical analysis. The subjects did not present any sign of imbalance that could impair the analysis or cause any episode of falling. The offline FPPA was measured between the line from the marker on the midpoint of the ankle malleoli to the midpoint of the femoral condyles and the line from the proximal thigh along with a line from the ASIS to approximately $30 \mathrm{~cm}$ above the knee, at the 
A.C. Barbosa et al., Gluteal activation and frontal plane projection

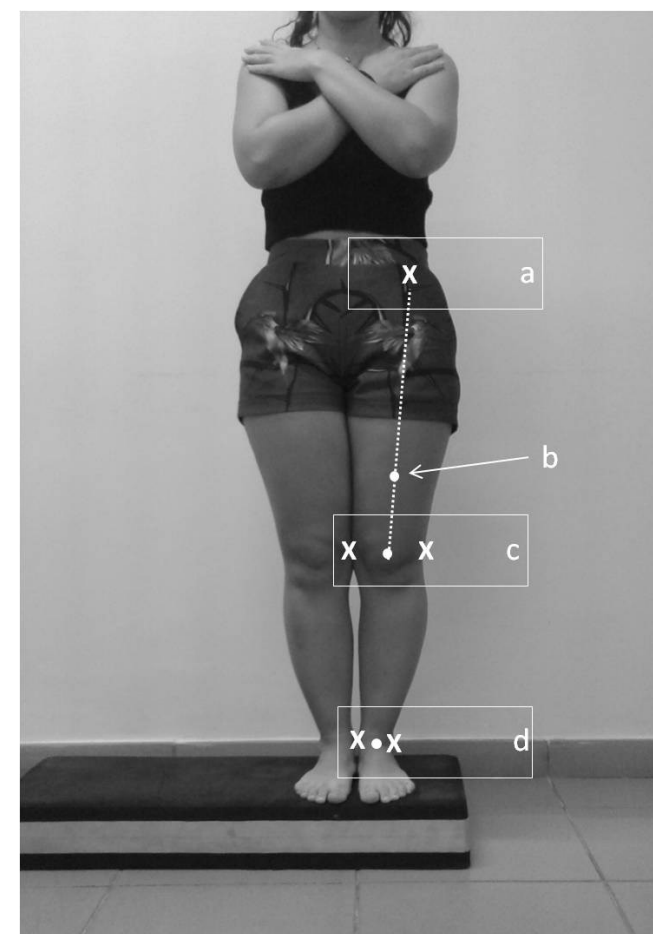

Figure 1. Landmarks position:

a. the anterior superior iliac crest (ASIS);

b. $30 \mathrm{~cm}$ above the knee on the proximal thigh along with a line from the ASIS;

c. the midpoint of the femoral condyles;

d. the midpoint of the ankle malleoli

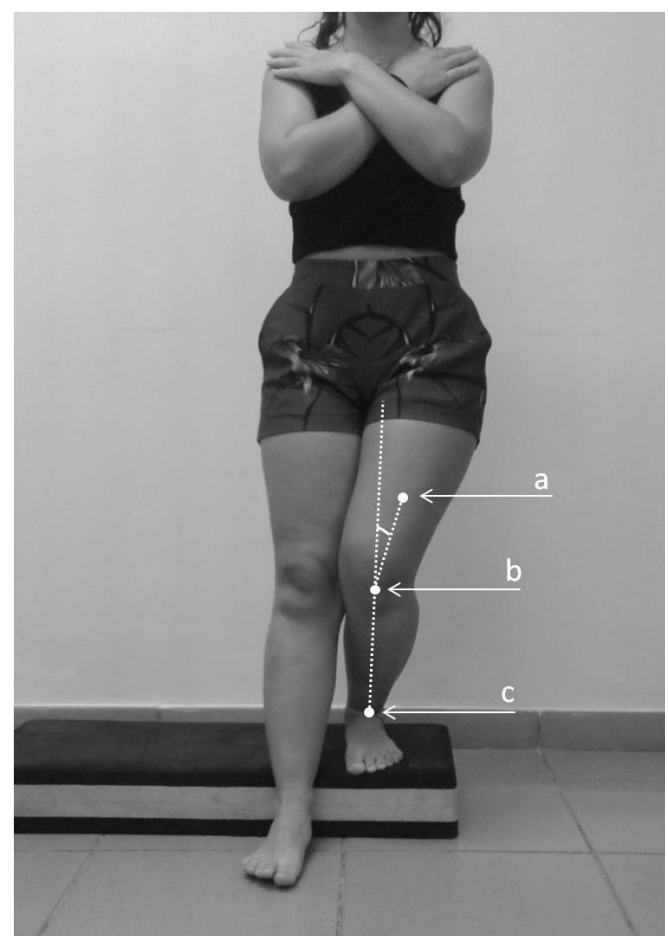

Figure 2. The frontal plane projection angle (FPPA): measured between the line from marker 'c' (on the midpoint of the ankle malleoli) to the midpoint of marker ' $b$ ' (on the midpoint of the femoral condyles) and the line from marker 'a' (on the proximal thigh along with a line from the ASIS to approximately $30 \mathrm{~cm}$ above the knee) to marker ' $b$ '. The frame that corresponded to the point of maximum knee flexion was used to measure the FPPA

erence electrode was placed on the left lateral humeral epicondyle. The sEMG signals were amplified and filtered (Butterworth fourth-order, 20-450 Hz bandpass filter, $60 \mathrm{~Hz}$ notch filter). All pieces of information were recorded and processed with the Miotec Suite ${ }^{\circledR}$ software (Miotec Biomedical Equipment, Porto Alegre, RS, Brazil). Prior to sEMG electrode placement, the skin was cleaned with $70 \%$ alcohol to eliminate residual fat, which was followed by an exfoliation with specific sandpaper for skin and the second cleaning with alcohol. Gluteus maximus electrodes were placed over the muscle belly, midway between the second sacral vertebra and the greater trochanter [10]. Gluteus medius (posterior fibres) electrodes were placed 33\% of the distance between the posterior ilium and the greater trochanter [24, 25].

The maximal voluntary isometric contraction (MVIC) was used to normalize the sEMG signal. For the gluteus medius, the subject was positioned in side-lying with the test lower limb uppermost. The thigh and leg were extended and the lower limb in line with the trunk. The hip and knee of the untested limb were in flexion 
to provide stability. The subject performed abduction about $30^{\circ}$ from the midline, and the examiner resisted manually just above the malleolus. For the gluteus maximus, the subject was placed in the prone position with a pillow placed under the pelvis to provide hip flexion at approximately $10-15^{\circ}$. The subject extended the thigh with the knee flexed at $90^{\circ}$ through the available hip-extension range of motion. The rater resisted manually at the distal thigh [26]. Verbal encouragement was given with each trial.

\section{Statistical analysis}

Normality was tested by the Shapiro-Wilk test. Correlation among normalized sEMG data, limb (right or left), and FPPA $\left(>\right.$ or $\left.<15^{\circ}\right)$ were analysed with Pearson's coefficient. The independent $t$ test was used to assess differences between sides - classified using the FPPA $\left(>\right.$ or $\left.<15^{\circ}\right)$. Additionally, the multivariate test principal component analysis (PCA) was performed to assess the cumulative variance of the variables. Alpha levels were set at 0.05 for all tests. The SPSS for Windows software, version 18.0 (SPSS Inc., Chicago, USA) was applied in all statistical analysis.

\section{Ethical approval}

The research related to human use has been complied with all the relevant national regulations and institutional policies, has followed the tenets of the Declaration of Helsinki, and has been approved by the authors' institutional review board or an equivalent committee.

The Federal University of Juiz de Fora Ethics Committeeapprovedthisstudy(CAAE44416315.1.0000.5147). The participants were informed about the study details and signed the informed consent form prior to participation.

\section{Informed consent}

Informed consent has been obtained from all individuals included in this study.

\section{Results}

None of the subjects reported any localized muscle pain during MVIC or while performing the step-down test. The FPPA was positively correlated with gluteus maximus activation $(r=0.40, p=0.008)$ and with the limb's side $(r=0.30, p=0.04)$. Also, a correlation was observed between the right and left gluteus maximus $(r=0.65, p=0.001)$. Two components were extracted from PCA, explaining $73 \%$ of the variance. PCA showed

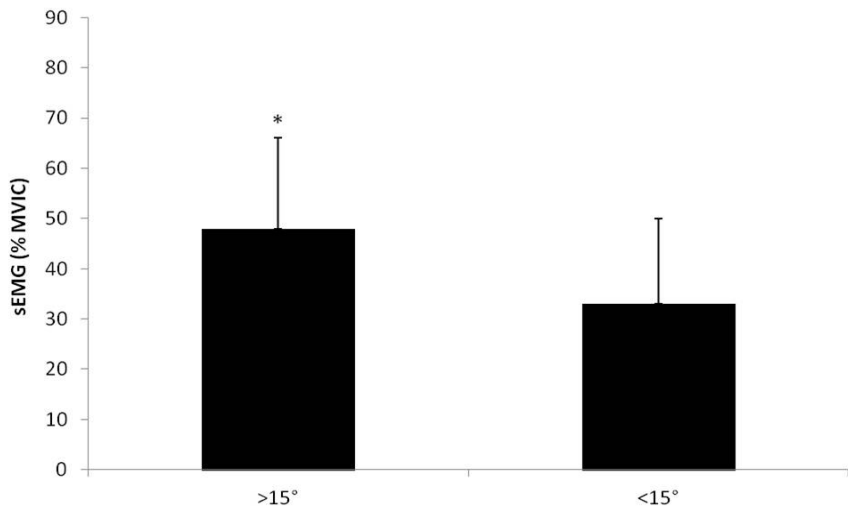

sEMG - surface electromyography, MVIC - maximal voluntary isometric contraction * significant difference $(p<0.05)$

Figure 3. Comparison of the gluteus maximus activation by surface electromyography in individuals with frontal plane projection angle above and below $15^{\circ}$

the gluteus maximus (right, 0.95; left, 0.78) explaining $48 \%$ of the cumulative variance of the first component and the gluteus medius (right, 0.41 ; left, 0.77) explaining additional $25 \%$ of the variance of the second component. Differences in muscle activation were found when FPPA was an independent variable. The gluteus maximus activation was higher on the side with angles above $15^{\circ}(48 \pm 18 \%$ vs. $33 \pm 17 \%$; $p=0.02$, Figure 3 ), with no difference for other comparisons.

\section{Discussion}

The results showed an increased activation of the gluteus maximus during the step-down test on the affected side, suggesting a decreased neuromuscular efficiency, as greater muscle recruitment is needed to perform the task. Biomechanical analysis showed posterior fibres of gluteus maximus acting as hip external rotators from 0 to $90^{\circ}$ of flexion combined with posterior fibres of the gluteus medius [27], with both muscles stabilizing the knee-hip complex in the frontal plane [28]. The majority of studies target PFP symptomatic subjects, but some research has hypothesized that PFP is caused by altered kinematics during weight bearing activities [4], so the presence of increased hip adduction-internal rotation could be indicative of preliminary findings for PFP development.

Holden et al. [13] suggested that baseline measures of knee valgus displacement $\geqslant 10.6^{\circ}$ were predictive of PFP with high sensitivity (75\%) and specificity (85\%) in female adolescents. The increased activation of gluteus maximus was positively correlated with an increased FPPA, suggesting greater activation of gluteus maximus when higher dynamic knee valgus was ob- 
A.C. Barbosa et al., Gluteal activation and frontal plane projection

served. The current results also indicate that the gluteus maximus is a major component to explain data variance when the task was performed and the dynamic knee valgus was perceived. Such combined data suggest the gluteus maximus activation as a predisposing factor to detect dynamic knee valgus and the development of PFP. Femoral internal rotation and adduction are thought to be controlled by gluteus maximus activation during unilateral tasks [29] and the current results suggest an increased activation of the muscle during step-down weight bearing to counteract the demand to maintain optimal alignment at the hip-knee complex. Similarly, Souza and Powers [10] reported increased activity of the gluteus maximus during the step-down task in females with PFP compared with the control group. Hollman et al. [30] showed the transverse-plane hip motion and hip extensor strength associated with frontal-plane knee kinematics during a jump-landing task. A systematic review noted females who presented PFP also showing deficits in hip extensor muscle strength [16], and a recent study found FPPA-peak values negatively correlated with the strength of hip abduction and posterolateral complex only for the group without PFP (FPPA-peak around $7^{\circ}$ ) [11]. The study assessed the relationship between the FPPA and hip and trunk muscle strength in women with and without PFP. However, individuals from PFP group with an average FPPA-peak smaller than $13^{\circ}$ were considered, which impairs any comparisons with the present study. Another research proved gluteus maximus activation to be negatively correlated with knee valgus during a step-down test in healthy young women [29], but the knee valgus angle range was again lower (5.3-6.4 $\left.{ }^{\circ}\right)$ than in the present study. Such differences in results may be explained by methodological issues concerning FPPA assessment and possible individual compensatory strategies during the step-down manoeuvre [11], such as lateral pelvic drop and the influence of external rotator muscles.

The results referring to gluteus medius were inconsistent with the presented outcomes: the muscle activation was not significantly correlated with FPPA, but the cumulative variance was explained by $25 \%$ at the second component. Such findings suggest a secondary role for gluteus medius during a single leg weight bearing task in women with increased FPPA and without PFP. A study assessed the activity of gluteus medius subdivisions [25] in healthy women presenting increased FPPA. The results showed that gluteus medius activation varied significantly across the subdivisions, with greater activation for mid and posterior subdivisions while performing a squat task [18]. Another study assessed the gluteus medius and other muscles recruitment during 2 different types of squat, showing different patterns of muscle activation when the task was performed at the same relative intensity by female athletes [31]. Such studies noted different levels of muscle activation owing to task and assessment variations, proving that gluteus medius activation could change depending on external loads and demands in coordinating the biomechanical function to keep the hip-knee complex stable. We speculate that such differences tend to be more evident when biomechanical abnormalities are present, like increased FPPA, demanding more from other powerful muscles surrounding the joint complex.

An important limitation of the present study is the cross-sectional design, which does not allow cause-effect inferences. Although the current data support the argument of greater activation of gluteus maximus as an attempt to provide dynamic stabilization of the hipknee complex and as a compensatory outcome of gluteus maximus weakness, knee-hip kinematics may be influenced by other factors, such as thigh muscles activation and joint coupling. Additional prospective studies are needed to provide definitive conclusions. Thus, it is possible that excessive FPPA subjects could benefit from exercises to modulate the activation of the gluteus maximus during weight bearing activities.

\section{Conclusions}

The present results provide preliminary evidence that young women with dynamic knee valgus exhibit increased gluteus maximus activation even before experiencing any usual symptoms of PFP, such as anterior knee pain. Additionally, gluteus maximus seems to be an important component to explain dynamic knee valgus in women without symptoms of PFP. We speculate that greater gluteus maximus activation is due to other muscle weakness and lower neuromuscular efficiency to stabilize the hip-knee complex in the frontal plane during a single leg weight bearing activity.

\section{Disclosure statement}

No author has any financial interest or received any financial benefit from this research.

\section{Conflict of interest}

The authors state no conflict of interest.

\section{References}

1. Powers CM. The influence of abnormal hip mechanics on knee injury: a biomechanical perspective. J Orthop 
Sports Phys Ther. 2010;40(2):42-51; doi: 10.2519/ jospt.2010.3337.

2. Souza RB, Draper CE, Fredericson M, Powers CM. Femur rotation and patellofemoral joint kinematics: a weightbearing magnetic resonance imaging analysis. J Orthop Sports Phys Ther. 2010;40(5):277-285; doi: 10.2519/ jospt.2010.3215.

3. Ford KR, Myer GD, Smith RL, Vianello RM, Seiwert SL, Hewett TE. A comparison of dynamic coronal plane excursion between matched male and female athletes when performing single leg landings. Clin Biomech. 2006; 21(1):33-40; doi: 10.1016/j.clinbiomech.2005.08.010.

4. Zeller BL, McCrory JL, Kibler WB, Uhl TL. Differences in kinematics and electromyographic activity between men and women during the single-legged squat. Am J Sports Med. 2003;31(3):449-456; doi: 10.1177/03635 465030310032101.

5. Ford KR, Myer GD, Toms HE, Hewett TE. Gender differences in the kinematics of unanticipated cutting in young athletes. Med Sci Sports Exerc. 2005;37(1):124129; doi: 10.1249/01.MSS.0000150087.95953.C3.

6. Pappas E, Hagins M, Sheikhzadeh A, Nordin M, Rose D. Biomechanical differences between unilateral and bilateral landings from a jump: gender differences. Clin J Sport Med. 2007;17(4):263-268; doi: 10.1097/JSM. 0b013e31811f415b.

7. Ford KR, Shapiro R, Myer GD, Van Den Bogert AJ, Hewett TE. Longitudinal sex differences during landing in knee abduction in young athletes. Med Sci Sports Exerc. 2010;42(10):1923-1931; doi: 10.1249/MSS.0b013e 3181dc99b1.

8. Carson DW, Ford KR. Sex differences in knee abduction during landing: a systematic review. Sports Health. 2011;3(4):373-382; doi: 10.1177/1941738111410180.

9. Fukuda TY, Melo WP, Zaffalon BM, Rossetto FM, Magalhães E, Bryk FF, et al. Hip posterolateral musculature strengthening in sedentary women with patellofemoral pain syndrome: a randomized controlled clinical trial with 1-year follow-up. J Orthop Sports Phys Ther. 2012; 42(10):823-830; doi: 10.2519/jospt.2012.4184.

10. Souza RB, Powers CM. Differences in hip kinematics, muscle strength, and muscle activation between subjects with and without patellofemoral pain. J Orthop Sports Phys Ther. 2009;39(1):12-19; doi: 10.2519/jospt. 2009.2885.

11. Almeida GP, Silva AP, França FJ, Magalhães MO, Burke TN, Marques AP. Relationship between frontal plane projection angle of the knee and hip and trunk strength in women with and without patellofemoral pain. J Back Musculoskelet Rehabil. 2016;29(2):259266; doi: 10.3233/BMR-150622.

12. Almeida GP, Carvalho E Silva AP, França FJ, Magalhães MO, Burke TN, Marques AP. Does anterior knee pain severity and function relate to the frontal plane projection angle and trunk and hip strength in women with patellofemoral pain? J Bodyw Mov Ther. 2015;19(3):558-564; doi: 10.1016/j.jbmt.2015.01.004.
13. Holden S, Boreham C, Doherty C, Delahunt E. Two-dimensional knee valgus displacement as a predictor of patellofemoral pain in adolescent females. Scand J Med Sci Sports. 2017;27(2):188-194; doi: 10.1111/sms.12633.

14. Bittencourt NF, Ocarino JM, Mendonça LD, Hewett TE, Fonseca ST. Foot and hip contributions to high frontal plane knee projection angle in athletes: a classification and regression tree approach. J Orthop Sports Phys Ther. 2012;42(12):996-1004; doi: 10.2519/jospt.2012.4041.

15. Powers CM. The influence of altered lower-extremity kinematics on patellofemoral joint dysfunction: a theoretical perspective. J Orthop Sports Phys Ther. 2003; 33(11):639-646; doi: 10.2519/jospt.2003.33.11.639.

16. Van Cant J, Pineux C, Pitance L, Feipel V. Hip muscle strength and endurance in females with patellofemoral pain: a systematic review with meta-analysis. Int J Sports Phys Ther. 2014;9(5):564-582.

17. Delp SL, Hess WE, Hungerford DS, Jones LC. Variation of rotation moment arms with hip flexion. J Biomech. 1999; 32(5):493-501; doi: 10.1016/S0021-9290(99)00032-9.

18. Barbosa AC, Carvalho RA, Bonifácio DN, Martins FL, Barbosa MC. Increased activation amplitude levels of gluteus medius in women during isometric and dynamic conditions following a 4-week protocol of low-load eccentric exercises. PhysiotherRes Int. 2016;21(4):257263; doi: 10.1002/pri.1643.

19. Saper MG, Shneider DA. Diagnosis and treatment of lateral patellar compression syndrome. Arthrosc Tech. 2014;3(5):e633-e638; doi:10.1016/j.eats.2014.07.004.

20. Ferreira EAG, Duarte M, Maldonado EP, Burke TN, Marques AP. Postural assessment software (PAS/SAPO): validation and reliability. Clinics. 2010;65(7):675-681; doi: 10.1590/S1807-59322010000700005.

21. Willson JD, Davis IS. Utility of the frontal plane projection angle in females with patellofemoral pain. J Orthop Sports Phys Ther. 2008;38(10):606-615; doi: 10.2519/ jospt.2008.2706.

22. Bolgla LA, Malone TR, UmbergerBR, Uhl TL. Hip strength and hip and knee kinematics during stair descent in females with and without patellofemoral pain syndrome. J Orthop Sports Phys Ther. 2008;38(1):12-18; doi: 10.2519/jospt.2008.2462.

23. Pantano KJ, White SC, Gilchrist LA, Leddy J. Differences in peak knee valgus angles between individuals with high and low Q-angles during a single limb squat. Clin Biomech. 2005;20(9):966-972; doi: 10.1016/j. clinbiomech.2005.05.008.

24. O’Sullivan K, Herbert E, Sainsbury D, McCreesh K, Clifford A. No difference in gluteus medius activation in women with mild patellofemoral pain. J Sport Rehabil. 2012;21(2):110-118; doi: 10.1123/jsr.21.2.110.

25. O’Sullivan K, Smith SM, Sainsbury D. Electromyographic analysis of the three subdivisions of gluteus medius during weight-bearing exercises. Sports Med Arthrosc Rehabil Ther Technol. 2010;2:17; doi: 10.1186/ 1758-2555-2-17. 


\section{HUMAN MOVEMENT}

A.C. Barbosa et al., Gluteal activation and frontal plane projection

26. Youdas JW, Adams KE, Bertucci JE, Brooks KJ, Nelson MM, Hollman JH. Muscle activation levels of the gluteus maximus and medius during standing hip-joint strengthening exercises using elastic-tubing resistance. J Sport Rehabil. 2014;23(1):1-11; doi: 10.1123/ jsr.2012-0082.

27. Robinson RL, Nee RJ. Analysis of hip strength in females seeking physical therapy treatment for unilateral patellofemoral pain syndrome. J Orthop Sports Phys Ther. 2007;37(5):232-238; doi: 10.2519/jospt.2007.2439.

28. McLean S, Walker K, Ford K, Myer G, Hewett T, van den Bogert AJ. Evaluation of a two dimensional analysis method as a screening and evaluation tool for anterior cruciate ligament injury. Br J Sports Med. 2005;39(6): 355-362; doi: 10.1136/bjsm.2005.018598.

29. Hollman JH, Ginos BE, Kozuchowski J, Vaughn AS, Krause DA, Youdas JW. Relationships between knee valgus, hip-muscle strength, and hip-muscle recruitment during a single-limb step-down. J Sport Rehabil. 2009;18(1):104-117; doi: 10.1123/jsr.18.1.104.

30. Hollman JH, Hohl JM, Kraft JL, Strauss JD, Traver KJ. Modulation of frontal-plane knee kinematics by hipextensor strength and gluteus maximus recruitment during a jump-landing task in healthy women. J Sport Rehabil. 2013;22(3):184-190; doi: 10.1123/jsr.22.3.184.

31. McCurdy K, O’Kelley E, Kutz M, Langford G, Ernest J, Torres M. Comparison of lower extremity EMG between the 2-leg squat and modified single-leg squat in female athletes. J Sport Rehabil. 2010;19(1):57-70; doi: 10.1123/ jsr.19.1.57. 